\title{
LETTERS
}

\section{Whole genome sequencing unlikely to be funded by government health plans}

The findings of the Personal Genome Project (PGP) are ambiguous because they tell only part of the story of genetic disease. ${ }^{1}$ It is common to use the words "genetic" and "inherited" interchangeably; however, there are two major components to genetic disease. The first is inherited genes, exhaustively examined in the PGP using whole genome sequencing, and the second, more important, is acquired (noninherited) genetic somatic mutations. In the dividing cells of the body, DNA replication is imperfect and results in random mutations, which are so common that fetal neurons contain 200-400 somatic mutations per cell by $15-21$ weeks postconception. ${ }^{2}$ No two cells in our body are genetically identical, and the impact and complexity of this mosaicism on the phenotypic expression of disease is underestimated in general ${ }^{3}$ and unaccounted for in the PGP.

Many of the common diseases that our patients are concerned about are spo- radic and noninherited genetic disorders. Cancer is a disease of acquired mutations; sporadic cancer requires at least two somatic mutations in a single cell (clone). Individuals with an inherited familial mutation, (e.g., the BRCA mutation) need an additional somatic mutation to develop cancer. Clonal mutations resulting in proteinopathies (e.g., antibodies and $\mathrm{T}$-cell receptors) can lead to autoimmune disorders such as type 1 diabetes, multiple sclerosis and rheumatoid arthritis. Neurodegenerative proteinopathies include Alzheimer disease, Parkinson disease and amyotrophic lateral sclerosis (ALS). These clonal somatic mutations cannot be detected by whole genome sequencing of blood DNA.

Whole genome sequencing technology is impressive, and, as the cost of testing falls, it may become the technology of choice for specific genetic testing, such as prenatal, familial, pharmacogenetic or cancer tissue genetic studies. Nevertheless the cost of generating an interpretive report, the family physician's time for consultation and the need for genetic counselling will increase substantially. Owing to its limitations to only the inherited genome and lack of specificity (false positives), whole genome sequencing is unlikely to be useful or interpretable as a laboratory screening test, let alone be funded by provincial health systems as a routine test.

\section{Tony Morris MD}

Pathologist, Red Deer Regional Hospital Centre, Red Deer, Alta.

Cite as: CMAJ 2018 April 23;190:E513. doi: $10.1503 / \mathrm{cmaj} .69223$

\section{References}

1. Reuter MS, Walker S, Thiruvahindrapuram B, et al. The Personal Genome Project Canada: findings from whole genome sequences of the inaugural 56 participants. CMAJ 2018;190:E126-36.

2. Bae T, Tomasini L, Mariani J, et al. Different mutational rates and mechanisms in human cells at pregastrulation and neurogenesis. Science 2018; 359:550-5.

3. Campbell IM, Shaw CA, Stankiewicz P, et al. Somatic mosaicism: implications for disease and transmission genetics. Trends Genet 2015;31:382-92.

Competing interests: None declared. 